\title{
Computational Fluid Dynamic Study On The Decomposition Of Methane Gas Into Hydrogen And Solid Carbon In A Packed Bed Fluid Catalytic Cracking Reactor
}

\author{
Ibrahim, S., Onifade, K.R., Kovo, A.S. Otaru, A.J. and Abdulkadir, M. \\ ${ }^{1}$ (Ovecon Engineering and Consultancy, P.O. Box 1730, Zaria, Nigeria) \\ 2,3,4\&5 (Department of Chemical Engineering, Federal Univeristy of Technology, PMB 065, Gidan Kwanu, \\ Minna, Niger State, Nigeria).
}

\begin{abstract}
This research was necesitated as a result of the development in petroleum refining technology in the last two decades which has brought the hydro processing reaction to a level of economic importance matching cracking and reforming. The work is to investigate the decomposition of methane gas into hydrogen and solid carbon.. Discretization methods were established numerically than analytically. Computational fluid dynamic modeling was carried out with the aid of chosen geometry, governing equation, properties of the fluid and time step. Result from this research shows that increase in time from 0 to 1000s yielded an increase in the formation of hydrogen from 0 to $42 \mathrm{~mol} / \mathrm{dm}^{3}$, increased carbon from 0 to $21 \mathrm{~mol} / \mathrm{dm}^{3}$, and decreased methane concentration from 50 to $29 \mathrm{~mol} / \mathrm{dm}^{3}$. This shows that methane decomposition is taking place.. Methane $\mathrm{CH}_{4}$ and Hydrogen $\mathrm{H}_{2}$ concentrations are approximately $0.18 \mathrm{~m}$ at the reactor mid section. The model can be modified to study the effect of carbon deposit on FCC catalyst of vacuum gas oil to produce reformate in packed bed.
\end{abstract}

Keywords: Carbon, Decomposition, Hydrogen, Methane, Modeling and Reactor.

\section{Introduction}

The Fluid Catalytic Cracking (FCC) is the primary conversion unit of many petroleum refineries around the world (Wilson, 1997). Raw crude oil consists of hydrocarbons ranging from light gases to residues boiling over $340^{\circ} \mathrm{C}$. These products of various boiling ranges are separated using a distillation column. However, distillation alone cannot produce sufficient amounts of lighter fractions such as gasoline to meet the public demand. Thus the FCC is needed to convert a portion of the heavy fractions into lighter products such as gasoline (Farag, 1993).

Cat crackers receive gas oil feed stocks which are cracked into lower molecular weight hydrocarbons which are either blended to finished products or routed to downstream units for processing with gasoline being the major end product (Coma and Martinez, 1994). A cat cracker is generally visualized as a reactor sitting on top of a catalyst regenerator with the reactions actually taking place in internal or external risers connecting the two. In practice, the configuration may be reversed, or the reactor and regenerator may be side by side. Both the reactor and catalyst regenerator are fluidized beds which allow continuous flow of feedstock and catalyst. Steam is added between the reactor and regenerator to purge the spent catalyst of absorbed hydrocarbons. The spent catalyst is then regenerated by burning off the coke, resulting in emissions of carbon monoxide (CO) and other pollutants. The main source of facility air emissions is the catalyst regenerator flue gas vent (Den Hollander et al., 2001).

Modeling of the riser reactor of an FCC unit is quite complex because of presence of gas in the riser, involvement of physical and chemical rates steps and its strong interaction with the regenerator (Ali and Rohani, 1997). Nevertheless, considering effort is made by various workers in all the above aspect of riser modeling.

Comsolmultiphysics simulation environment facilitates all the steps in the modeling process that is defining the geometry, meshing, specifying the physics, solving and then visualizing the result it also serves as a platform for the application of specific modules set-up is quick to a number of predefined physics interface for application ranging from fluid flow and heat transfer to material properties and boundary can all be spatially varying time -dependent variable. Physics interface can mix freely with multiphysics couple with any application specific module.

This work investigates the thermal decomposition of methane into hydrogen and solid carbon. The model briefly describe the isothermal process occurring in the FCC packed bed reactor, simulated in the comsol Reaction Engineering Lab. 


\section{Research methodology}

This study involve the catalytic decomposition of methane to hydrogen in a FCC reactor using Computational Fluid Dynamics (CFD). A model was developed in this study. The effect that the carbon deposits have on the fluid flow was investigated. The simulation takes place in comsol multiphysics, taking both time and space dependencies into account.

\section{The Fluid Catalytic Packed Bed Reactor}

The model consists of the FCC reactor packed with zeolite Y catalyst where methane gas is charged into it and it decomposed to carbon and hydrogen by catalytic cracking as shown in the Figure 1. The coloured region is the zeolite packed region of the reactor while the plain region is the region gas entry and exit from the reactor. A flow reactor is set up in 2D. Methane enters from the left and reacts in the porous catalytic bed in the mid-section of the geometry.

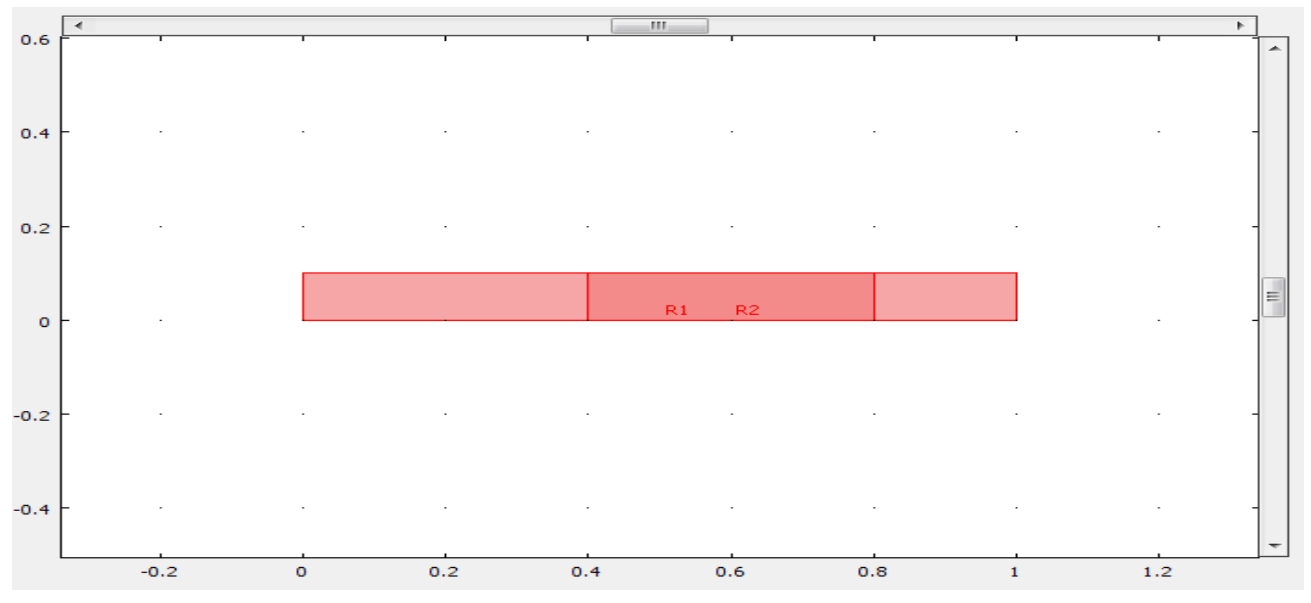

Time (sec)

Figure 1: FCC Model showing the entering and exiting gas and the zeolite packed region of the reactor.

The model is geometry modeling which is applicable to CFD and is represented as Figure 1

\section{Problem Statement}

Fifty $\mathrm{mol} / \mathrm{m}^{3}$ of methane gas is charged into an FCC reactor where it is flowing through a packed bed of zeolite $\mathrm{Y}$ catalyst at temperature of $727^{\circ} \mathrm{C}$. The methane is cracked on the zeolite catalyst producing carbon deposit on the catalyst surface and hydrogen gas. The hydrogen gas exit the contacting bed at temperature of $727^{\circ} \mathrm{C}$. Determine the effect that the carbon deposit have on fluid flow taking both space and time dependencies into account. 
Development of CFD Modeling

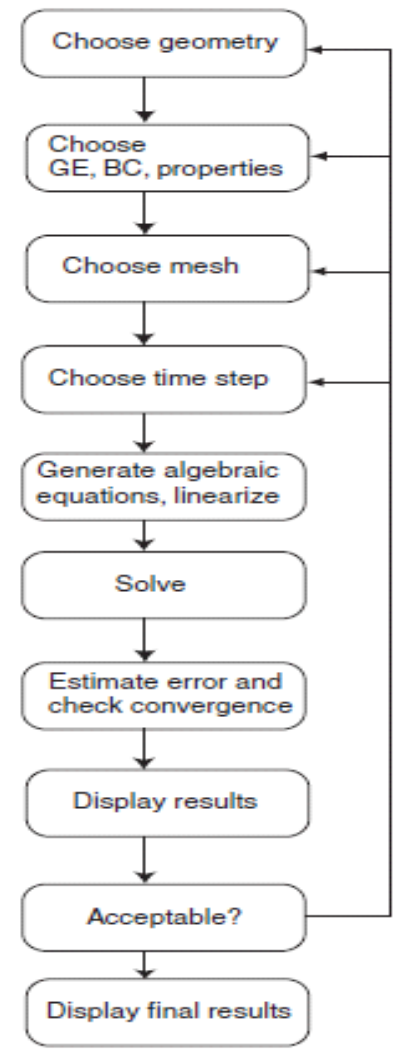

Figure 2: Flowchart of CFD model development.

\section{Geometry}

The research work involves the decomposition of methane to carbon and hydrogen gas in catalytic packed bed reactor. The packed bed fluid catalytic reactor is represented by a 2D geometry as seen in Figure 3.

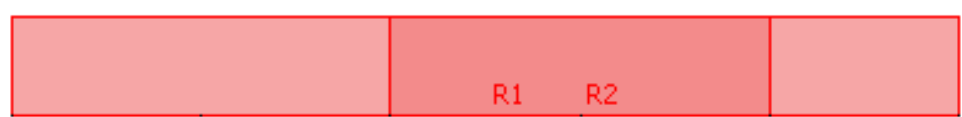

Figure 3: The Packed Bed Fluid Catalytic Reactor Model

\section{Axis and Grid Settings}

Table 1 Coordinate for drawing the geometry of the FCC packed bed reactor in $2 \mathrm{D}$

\begin{tabular}{llll}
\hline Size & \multicolumn{2}{l}{ Position } \\
\hline Width & 1 & $\mathrm{x}$ & 0 \\
Height & 0.1 & $\mathrm{y}$ & 0 \\
\hline
\end{tabular}

Table 2 Coordinate for drawing the geometry of the packed bed region of the FCC packed bed reactor in $2 D$

\begin{tabular}{llll}
\hline Size & \multicolumn{3}{c}{ Position } \\
\hline Width & 0.4 & $\mathrm{x}$ & 0.4 \\
Height & 0.1 & $\mathrm{y}$ & 0 \\
\hline
\end{tabular}


The coordinate for drawing the geometry of the FCC packed bed reactor and the catalyst packed region of the reactor in 2D is shown in Table 1 and Table 2.

The governing equations

The governing equations used by comsol for the CFD simulation are mass transport equation for convection and diffusion which are described below.

\section{Model definition}

\section{Chemistry}

Methane decomposes over a Zeolite y catalyst according to the overall chemical reaction:

$\mathrm{CH}_{4}$

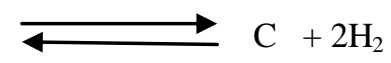

The following reaction rate expression has been reported in the literature (Shariff et-al, 2004): relating the rate of reaction and the concentration of various species is

$r=k \cdot \frac{p_{\mathrm{CH}_{4}-} \frac{p^{2} \mathrm{H}_{2}}{K_{p}}}{\left(1+k_{H} \sqrt{p_{H_{2}}}\right)^{2}}$

Where

$$
\begin{aligned}
& k=2.31 * 10^{-5} * \exp \left(20.492-\frac{104200 \mathrm{~J} / \mathrm{mol}}{R_{g} T}\right) \frac{\mathrm{mol}}{\mathrm{m}^{3} \cdot s \cdot b a r} \\
& k_{H}=\exp \left(\frac{\frac{163200 \mathrm{~J}}{\mathrm{~mol}}}{R_{g} T}-22.426\right)(\mathrm{bar})^{-1 / 2}
\end{aligned}
$$

And

$K_{p}=5.088 * 10^{5} * \exp \left(-\frac{91200 \mathrm{~J} / \mathrm{mol}}{R_{g} T}\right) \mathrm{bar}$

\section{Reactor model}

The first model in Comsol Reaction Engineering Lab .was set up This model treats the isothermal decomposition of methane (Equation 1) in a perfectly mixed reactor with constant volume. The species mass balances are summarized by

$\frac{d_{c_{i}}}{d t}=R_{i}$

The rate term, $R_{i}\left(\mathrm{~mol} /\left(\mathrm{m}^{3} \cdot \mathrm{s}\right)\right.$, takes into account the reaction stoichiometry, $v_{i}$, the reaction rate, $r\left(\mathrm{~mol} /\left(\mathrm{m}^{3} \cdot \mathrm{s}\right)\right.$, and the catalyst activity, $a$ :

$R_{i}=V_{i} r_{a}$

The mass balances of the reacting species are then

$\frac{d_{c_{C H}}}{d t}=-r_{a}$

$\frac{d_{c_{c}}}{d t}=r_{a}$

$\frac{d_{c_{H 2}}}{d t}=2 r_{a}$

The time dependence of the catalytic activity is expressed by the ODE

$p=R_{g} T\left(C_{C H 4}+C_{H 2}\right)$

Where 
$k_{a}=\exp \left(\frac{\frac{135600 \mathrm{~J}}{\mathrm{~mol}}}{R_{g} T}-32.007\right)\left(\frac{\mathrm{m}^{3}}{\mathrm{~mol}}\right)^{3} \cdot \mathrm{s}$

Solving the mass balances provides the evolution of the species concentrations over time. The fact that carbon is in the solid phase is taken into account by removing its effect on gas phase physical properties. The pressure in the reactor is a function of only the methane and hydrogen concentrations:

$p=R_{g} T\left(C_{C H 4}+C_{H 2}\right)$

\section{Space- and time-dependent Model}

The second model is solved in comsol multiphysics and takes both fluid flow and the chemical reaction into account.

The flow reactor is set up in $2 \mathrm{D}$, as illustrated below:

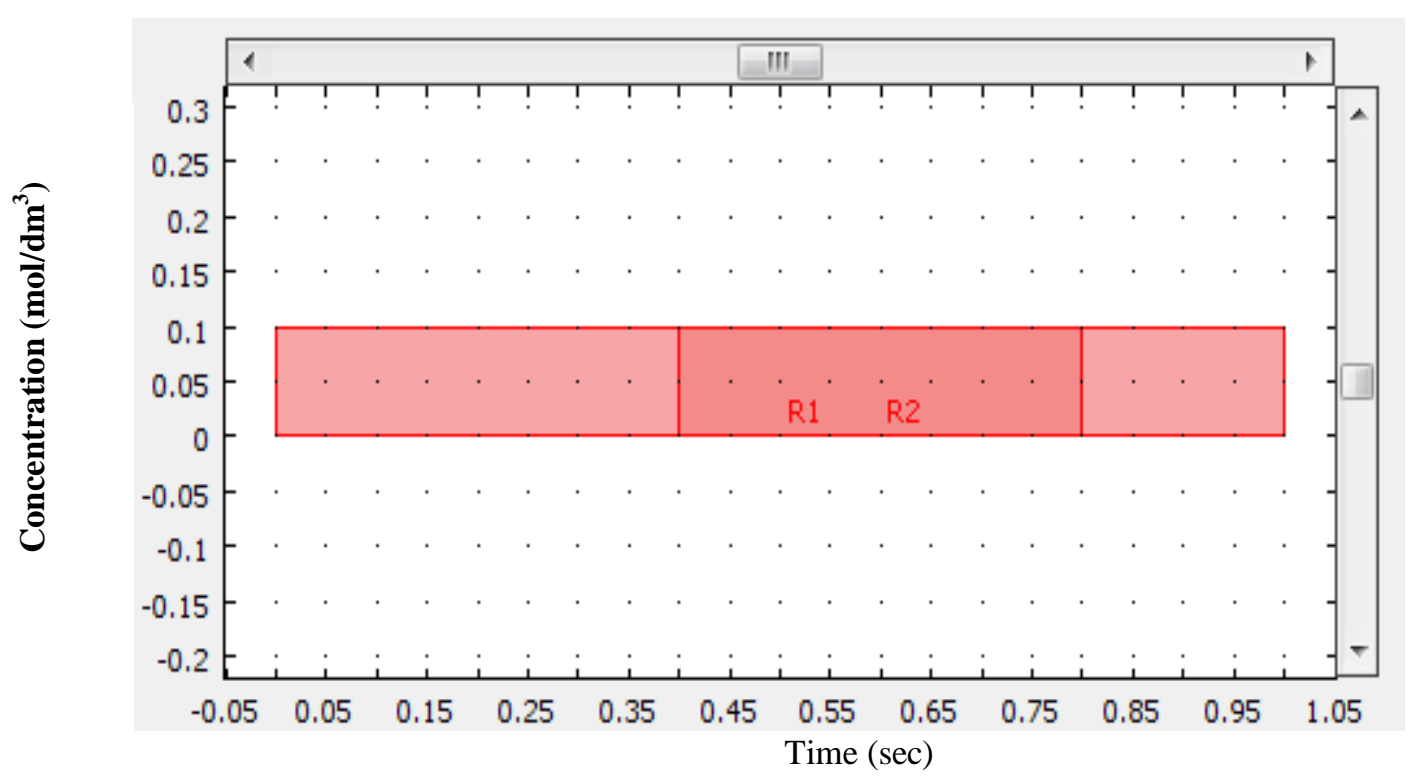

Figure 4: A flow reactor is set up in 2D. Methane enters from the left and reacts in the porous catalytic bed catalytic bed in the mid-section of the geometry.

Methane first flows through a free section of the reactor, and then encounters a porous catalytic bed where the decomposition reaction takes place.

\section{Procedure for Solving the Computational Fluid Dynamics Models.}

This model deals with a phenomenon occurring in a 2D domain (convection- diffusion) coupled to another phenomenon occurring only at the 1D boundary of the 2D domain (diffusion-reaction). The comsol multiphysics implementation is straightforward in every step except for the definition of the 1D problem, which requires some mathematical background. A weak-form application modes of comsol multiphysics was used for modeling PDEs on boundaries, edges, or points. Adding the 1D boundary equation in the 2D model, the Weak Form, Boundary application mode was used. This enables the formulation of the problem with the weak form instead of with the PDE form. An examination of the spatial diffusion on the boundary shows that only the flux tangential to the surface was defined. Therefore, in the weak-form specification the special tangential derivative variable was used. 


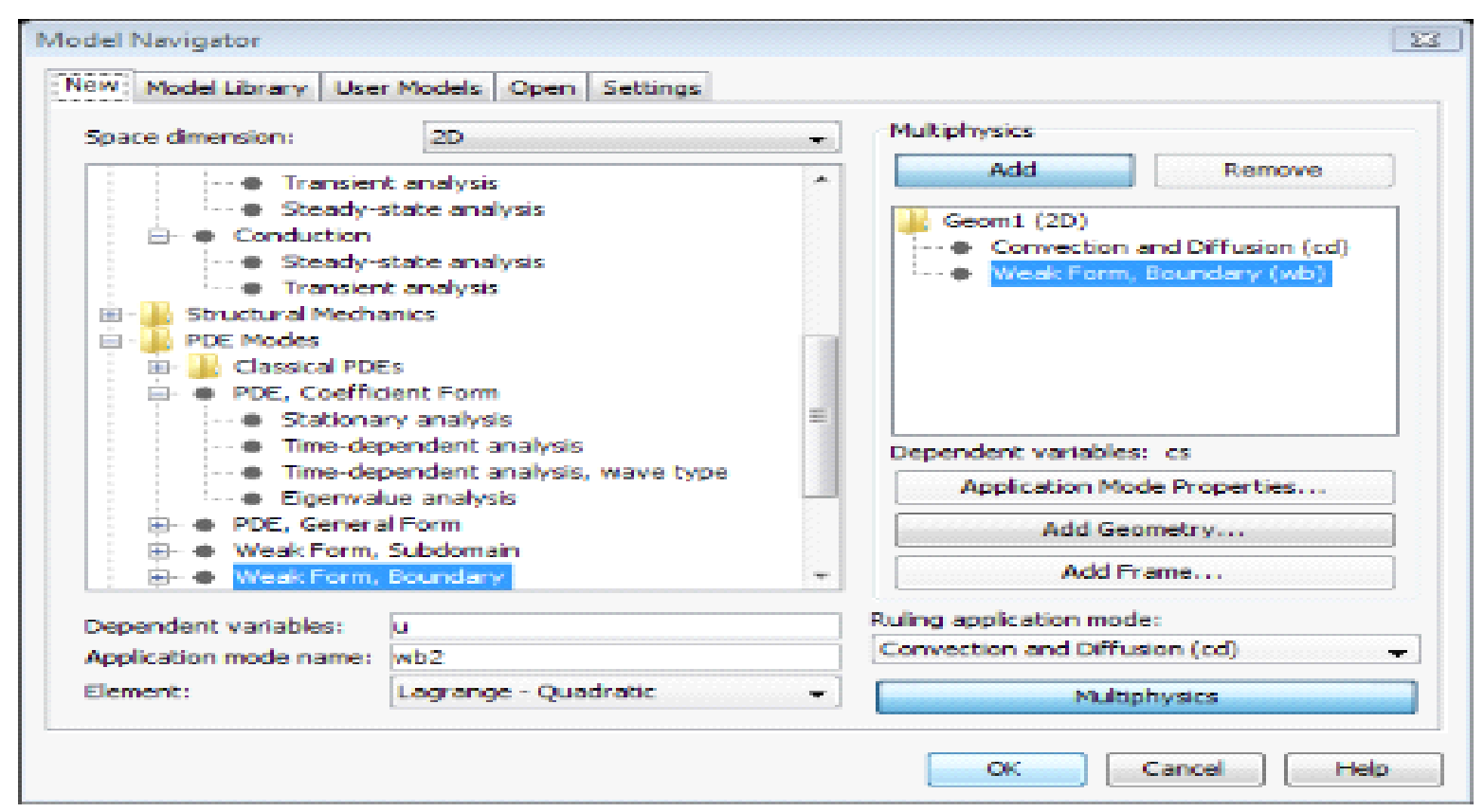

Figure 5: Model navigator of the comsolmultiphysics.

\section{Numerical methods}

All the governing equations were numerically solved in comsol multiphysics (version 3.5) using a stationary solver with a direct (UMFPACK) linear solver system. The residual convergence was limited to $10^{-6}$ for all variables. Grid independence was achieved at 57000 finite elements (Figure 5), after which the change in the maximum temperature was less than $0.1 \%$, change in maximum velocity was less than $1 \%$, concentration was less than $0.1 \%$.

\section{Results}

\section{Results and discusion}

The results of the computational fluid dynamics of transport and reaction on the active surface of a catalyst in an FCC riser are shown below:

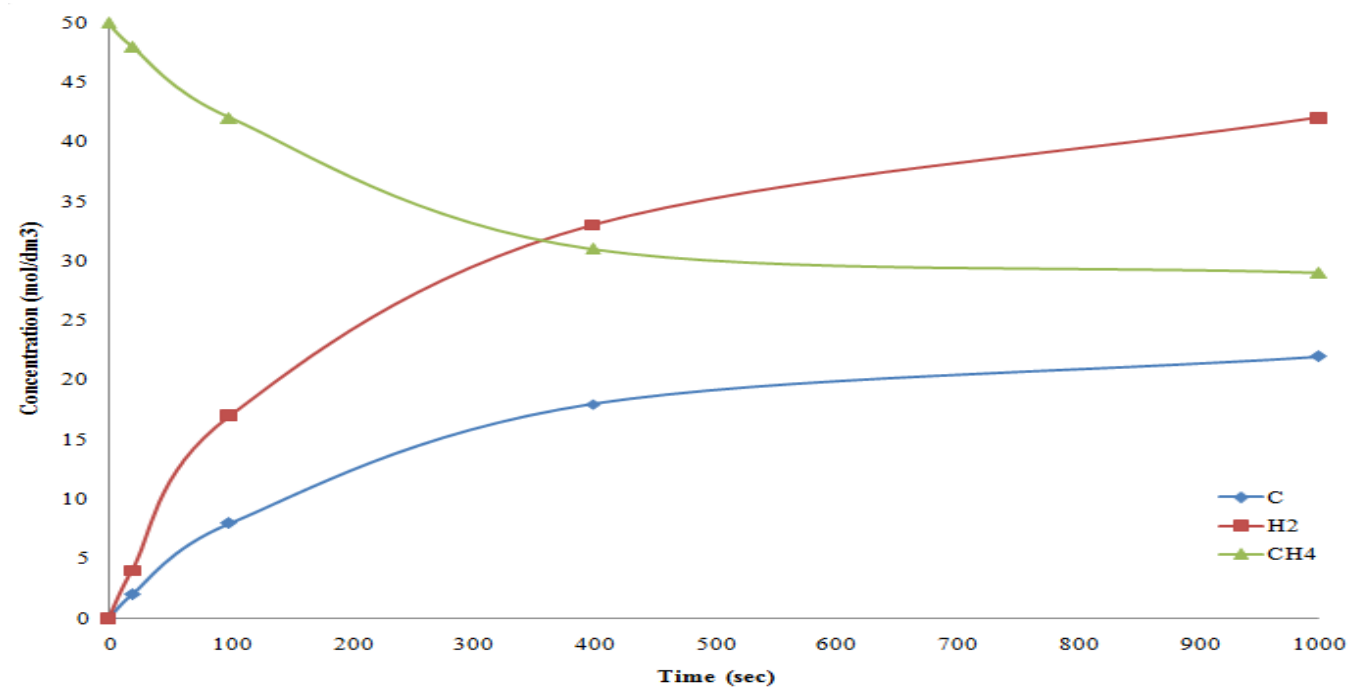

Figure 6: The concentration transients of methane decomposition over a zeolite Y catalyst. 


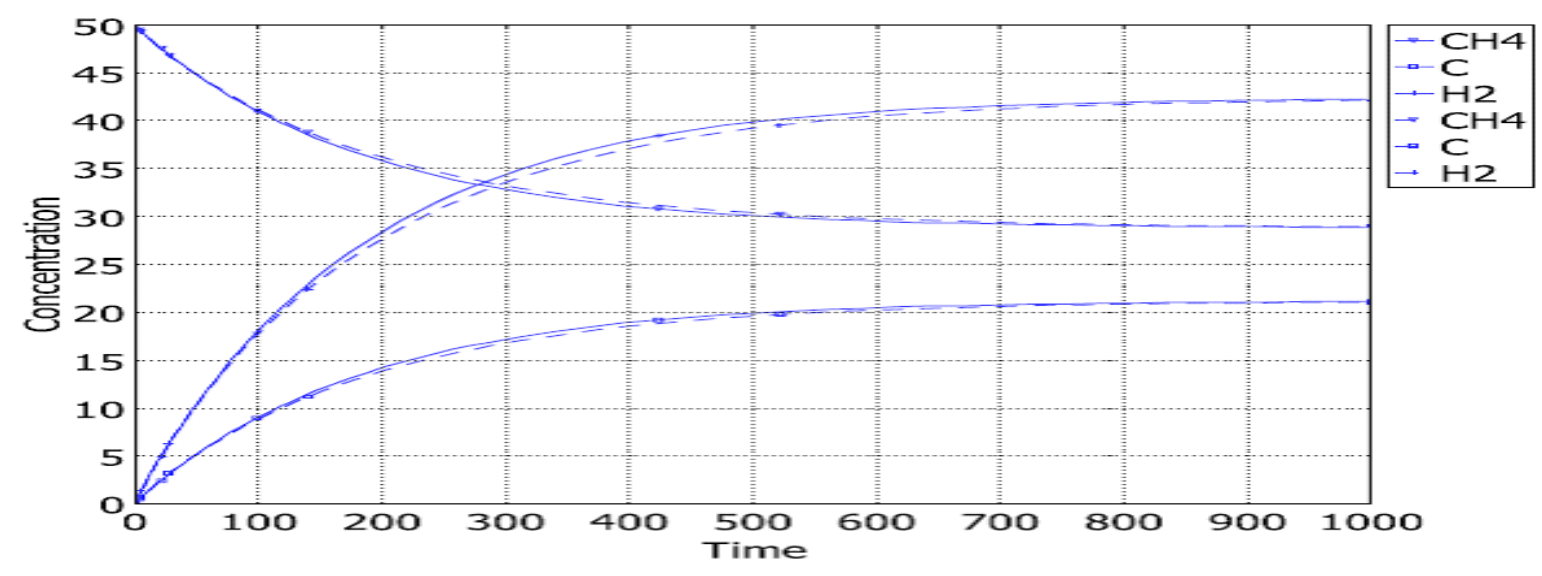

Figure 7: Concentration transients of methane, hydrogen, and deposited carbon with no deactivation present (solid lines) and with deactivation taken into account (dashed lines).

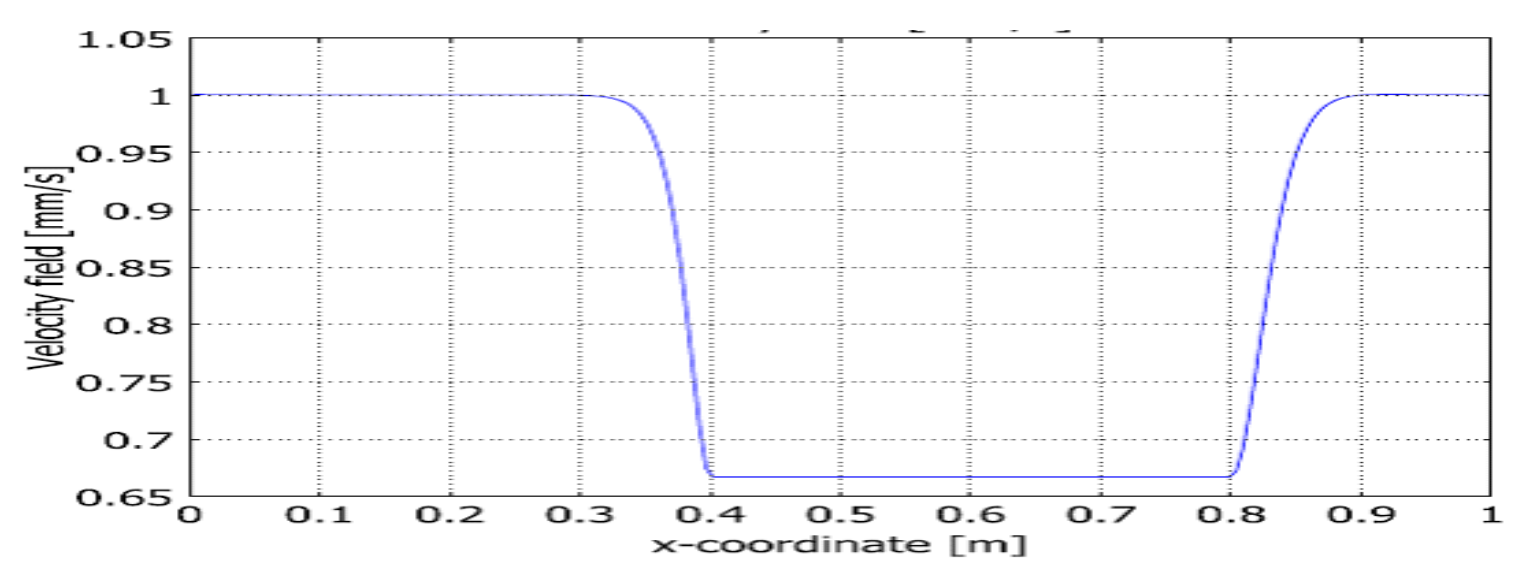

Figure 8: The variation of velocity flow field in the 2D reactor domain.

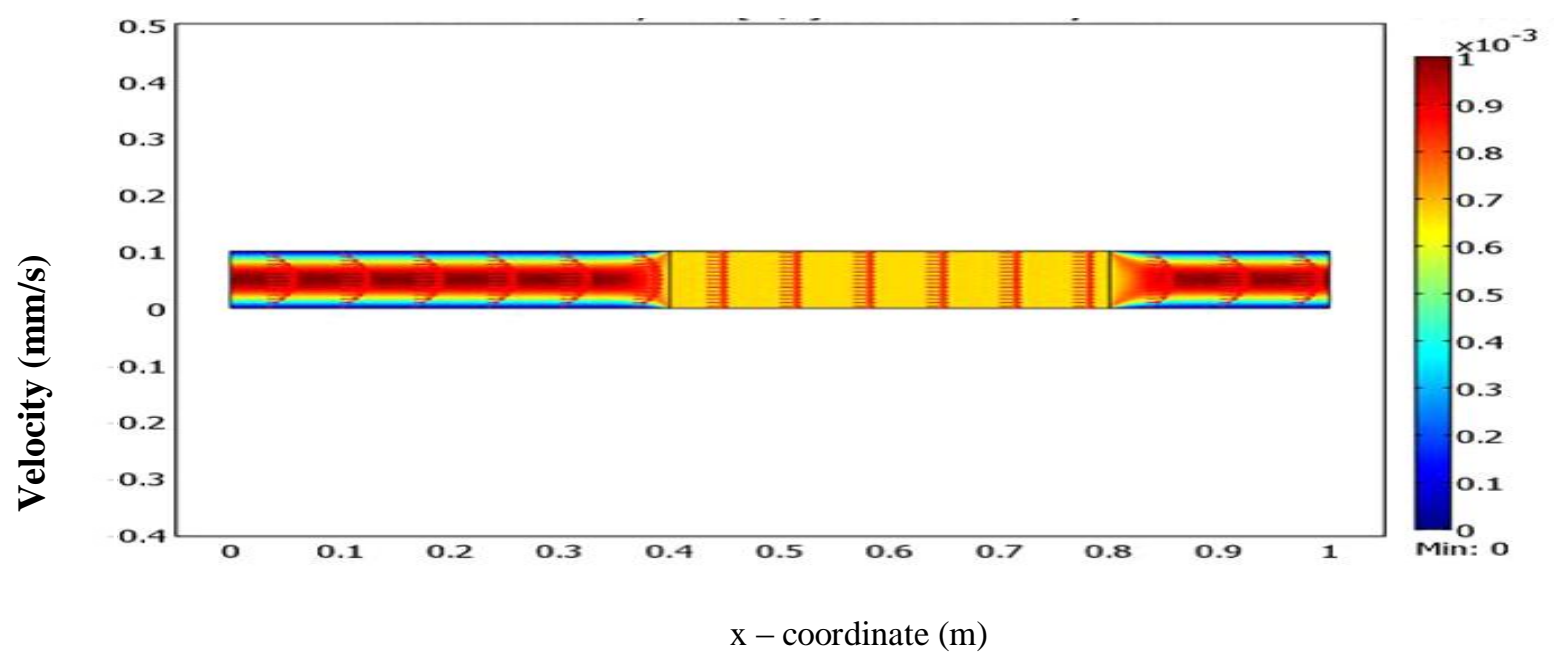

Figure 9: The variation of gas velocity along the reactor centerline. 


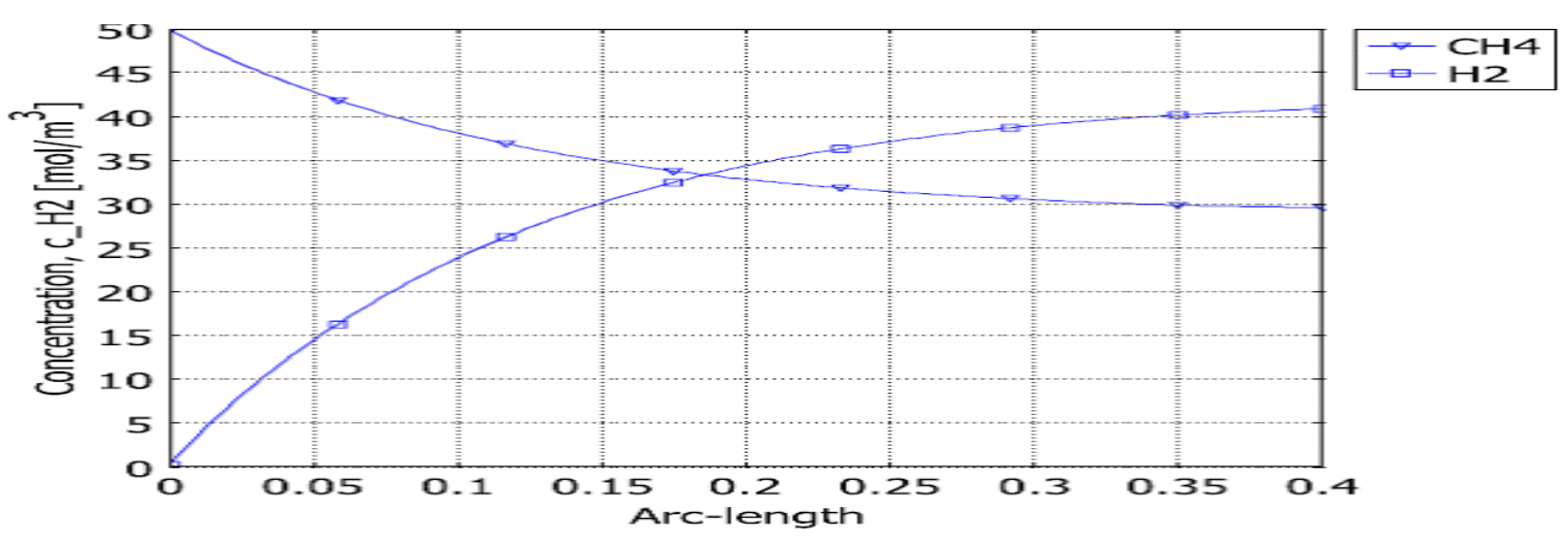

Figure 10: Methane and hydrogen concentrations as a function of the bed position.

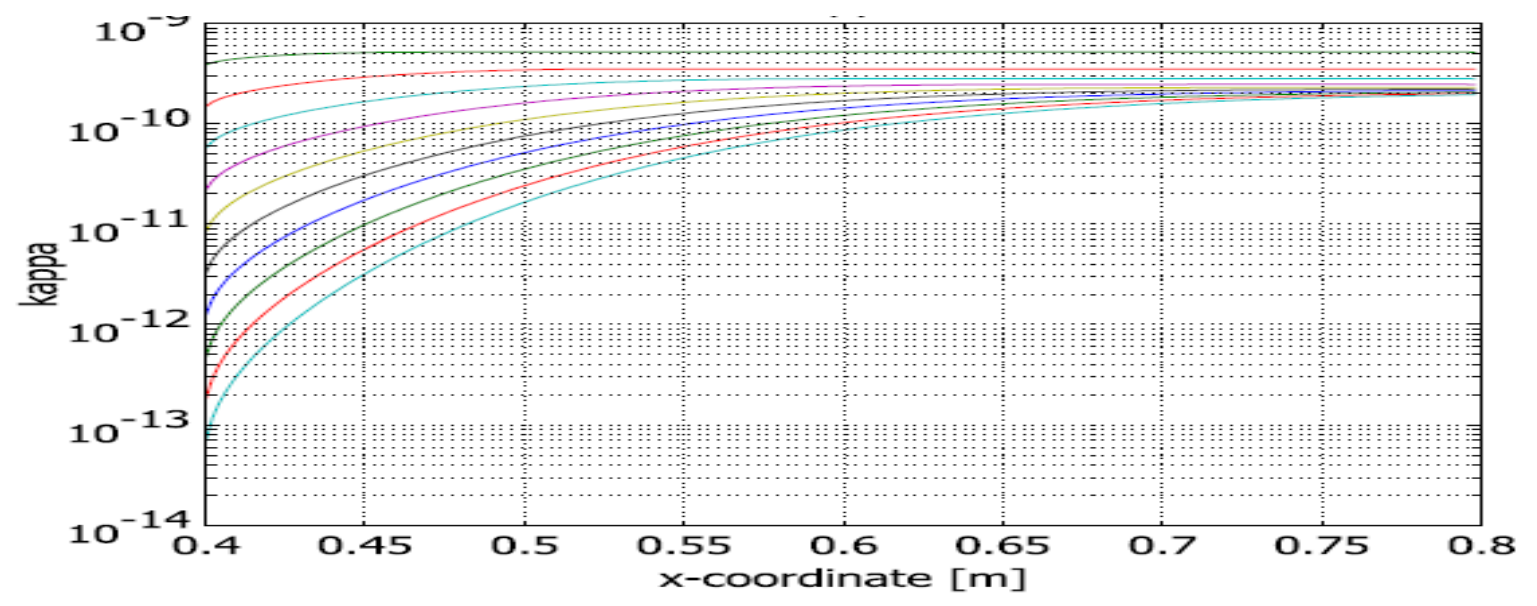

Figure 11: Permeability of packed catalytic bed as the decomposition of methane proceeds for 1,000 s.

Then time interval between each line is 1 .

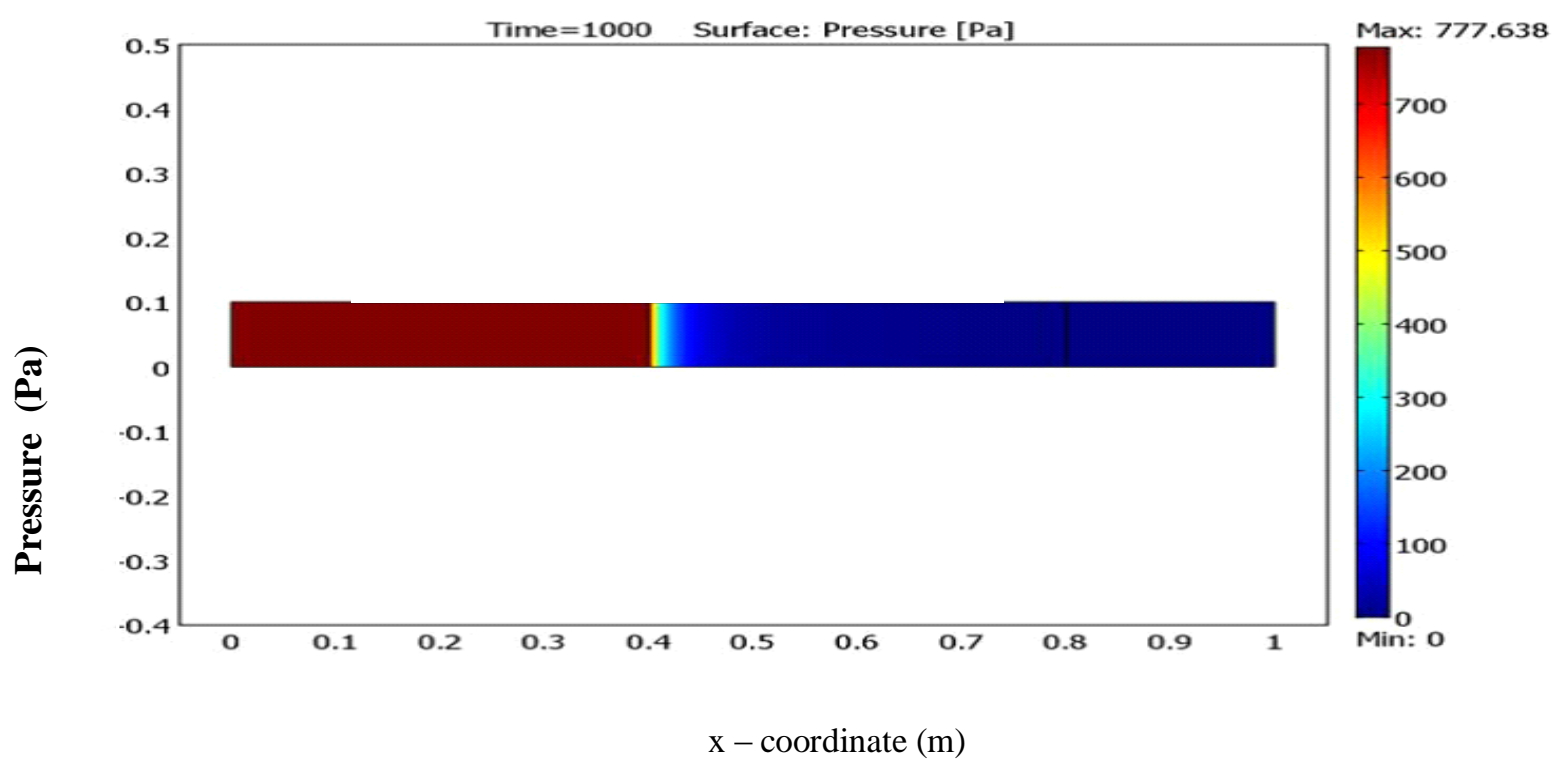

Figure 12: Distribution of pressure when methane decomposition has been allowed to occur for $1000 \mathrm{~s}$

(Pressure distribution across the 2D reactor domain). 


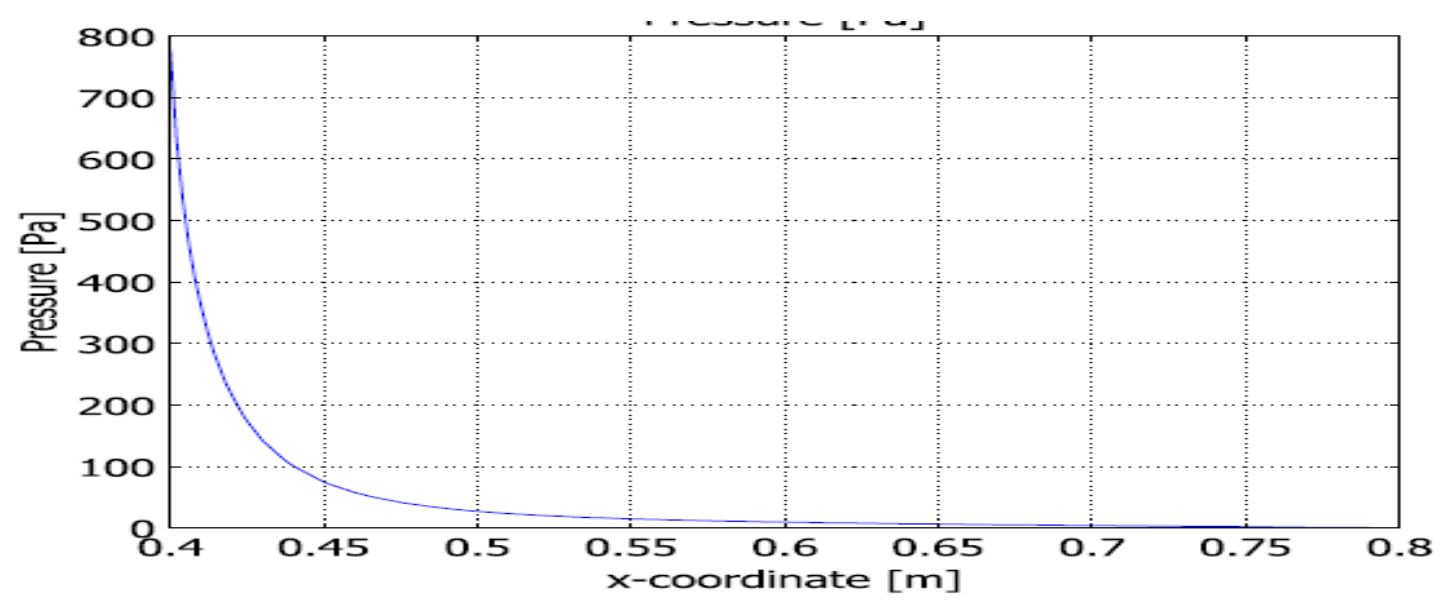

Figure 13: Distribution of pressure when methane decomposition has been allowed to occur for $1000 \mathrm{~s}$

(Pressure drop along the packed catalyst bed).

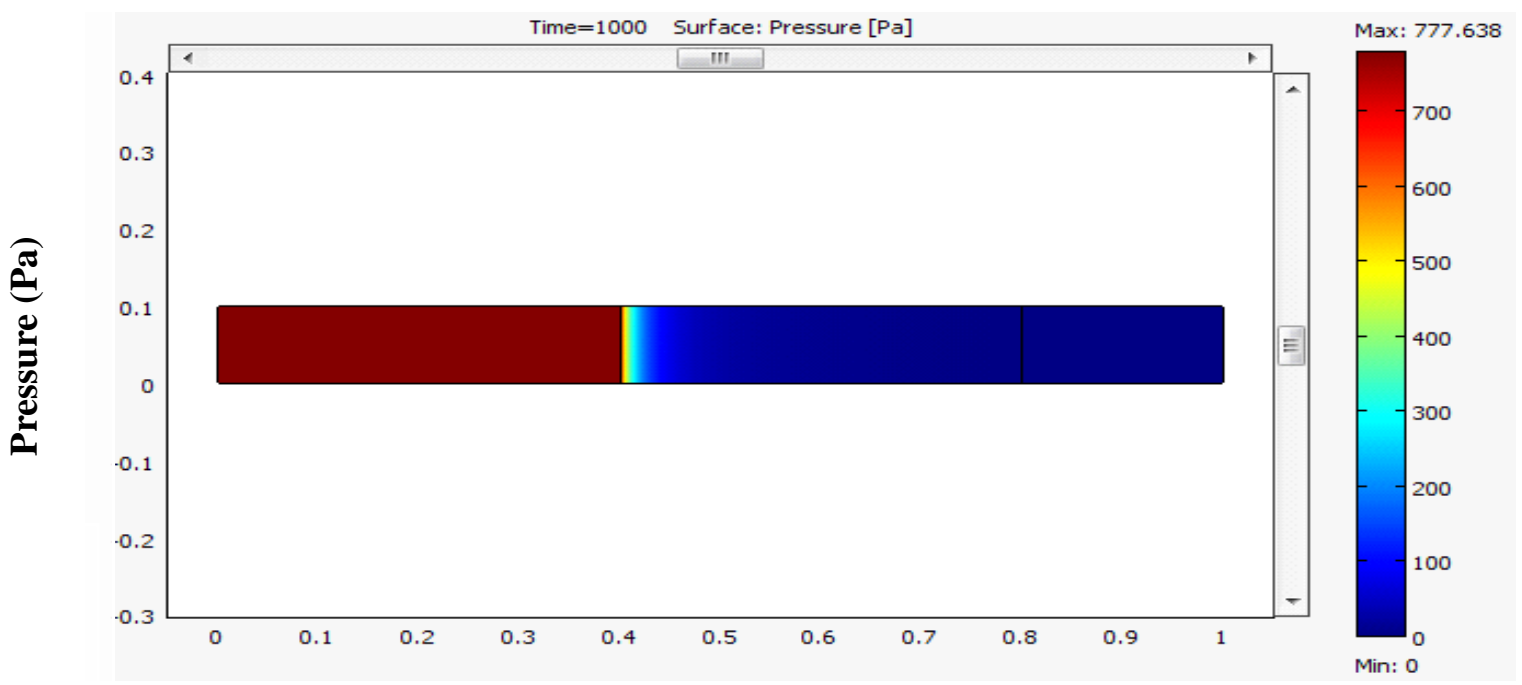

$\mathrm{x}$ - coordinate $(\mathrm{m})$

Figure 13: Distribution of pressure when methane decomposition has been allowed to occur for $1000 \mathrm{~s}$

(COMSOL, 2008).

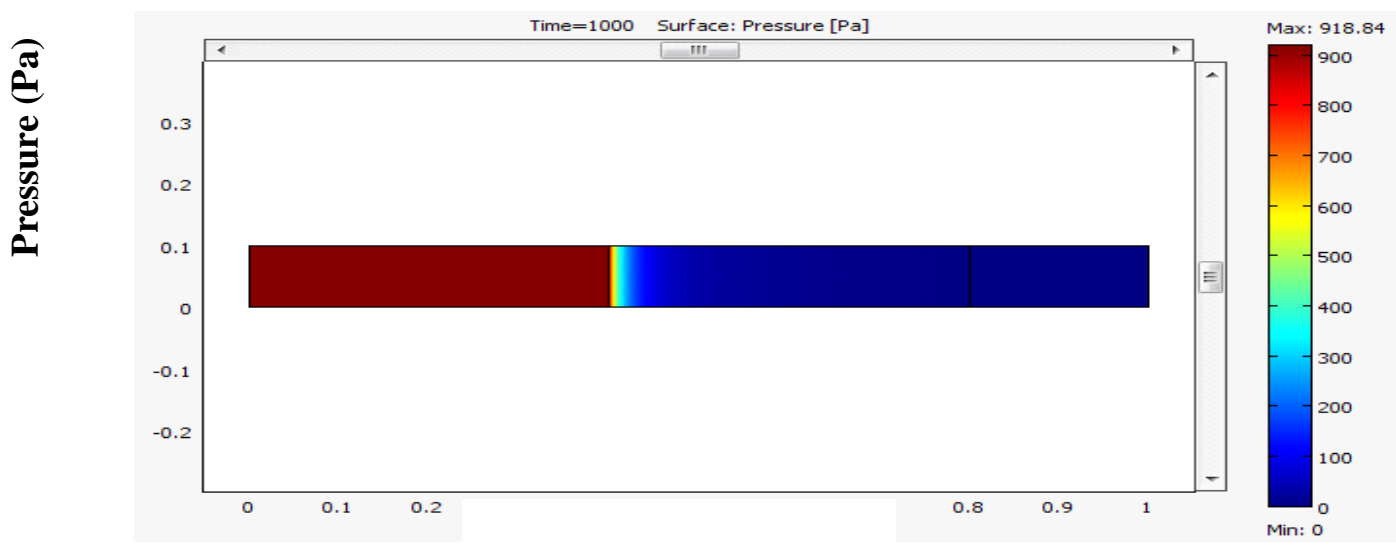

$\mathrm{x}$ - coordinate $(\mathrm{m})$

Figure 14: Distribution of pressure when methane decomposition has been allowed to occur for $1000 \mathrm{~s}$. 


\section{Discussion}

Figure 6 shows the concentration profile of methane decomposition over a zeoelite Y catalyst the plot shows that as the time of methane decomposition increase from 0 to $1000 \mathrm{~s}$, the concentration of carbon and hydrogen formed increase from 0 to $42 \mathrm{~mol} / \mathrm{dm}^{3}$. For hydrogen and carbon increase from 0 to $21 \mathrm{~mol} / \mathrm{dm}^{3}$ this shows that the formation of hydrogen is faster than that of carbon. Figure 6 also shows that as a reaction time increase from 0 to $1000 \mathrm{~s}$ the methane concentration decrease from 50 to $29 \mathrm{~mol} / \mathrm{dm}^{3}$. This shows that methane decomposition take place in the reactor. Also from Figure 6 the carbon deposition on catalyst is faster from time 0 to $400 \mathrm{~s}$ above $500 \mathrm{~s}$ carbon deposition is lower.

Figure 7 shows the concentration transients of methane hydrogen with catalyst deactivation included in the model and when catalyst deactivation was not included in the model. The dashed line shows when catalyst deactivation was taken into an account and solid line shows when catalyst deactivation was not taken into an account. Figure 7 shows that the concentration of carbon and hydrogen formed is less when catalyst deactivation is taken into an account compare to when catalyst deactivation was taken into an account. It can be deduce from the above discussion that carbon deposit on the catalyst affect the performance of the catalyst.

The following results concern a space- and time-dependent model simulated in comsolmultiphysics. Methane decomposition occurs in a porous region where solid catalyst particles are packed. Figures 8 and 9 show the velocity field across the reactor prior to carbon deposition. The 2D plot in Figure 8 shows that the velocity profile is parabolic in the free channel sections and close to constant in the porous domain. The line plot in Figure 9 shows the velocity along the reactor centerline.

Reactions take place in the packed catalytic bed located in the reactor mid section. Figure 10 shows the concentration profiles along the centerline of the bed. The methane and hydrogen concentrations are equal approximately $0.18 \mathrm{~m}$ into the bed. Figures 8 and 9 show that the velocity in the bed is about $0.67 \mathrm{~mm} / \mathrm{s}$, corresponding to a residence time of $270 \mathrm{~s}$. This result agrees with the findings from the reactor simulation, shown in Figures 6. Figure 4.6 shows the permeability of packed catalytic bed as the decomposition of methane proceeds for $1,000 \mathrm{~s}$ at a time interval of 1 between each line. Figures 12 and 13 show the pressure distribution across the reactor after methane decomposition has occurred for $1000 \mathrm{~s}$. The pressure drop is notably greater and occurs across the first $10 \mathrm{~cm}$ of the bed.

\section{Conclusion}

Based on results and the discussion of results obtained in this thesis the following conclusion can be reached:.

- Methane decomposition occurs in a porous region where solid catalyst particles are packed.

- Reaction was carried out in the packed catalytic bed located in the reactor'smid section.

- $\quad$ The permeability at the front end of the bed changes by four orders of magnitude during the first $1000 \mathrm{~s}$ of carbon deposition

- $\quad$ The methane and hydrogen concentrations are equal approximately $0.18 \mathrm{~m}$ into the bed.

The thesis has demonstrated how CFD can be used to see the effect of carbon deposit on FCC catalysts and it also show the effects of the fluid flow in FCC reactor.

\section{Acknowledgements}

Praised be to almighty Allah for his abundance grace and wisdom for seeing this work to completion.

\section{References}

[1]. Ali, H and Rohani. S., (1997) "Dynamic Modeling and Simulation of a Riser-Type Fluid Catalytic Cracking Unit". Chem. Eng. Technol. 20, pp 118-130.

[2]. Coma, A., and Martinez-Triguero, J. (1994) "Kinetics of Gas Oil Cracking and Catalyst Decay on SAPO-37 and USY Molecular Sieves", App Catal, 118, Pp.153-162.

[3]. Den Hollander, M.A., Makkee, M., and Moulijn, J .A (2001) Prediction of The performance of coked and regenerated fluid catalytic cracking catalyst mixtures opportunities for process flexibility ind . Eng. chem. Res., 40, 1602-1607.

[4]. Farag, H. (1993) "Catalytic Cracking of Hydrocarbons with Novel Metal Traps". PhD Thesis Dissertation, the University of Western Ontario, London-Ontario, Canada.

[5]. Wilson, J.W. (1997). Fluid catalytic cracking technology and operation .Oklahoma. Pennwell publishing company.

[6]. Zheng, Y .Y. (1994) . Dynamic modeling and simulation of catalytic cracking unit computing. Chem. Eng., 18, 39-44. 